\title{
Qual é a influência da cor da luz na fotossíntese? ${ }^{+*}$
}

\author{
Ronaldo Pereira de Melo Júnior ${ }^{1}$ \\ Colégio Militar do Recife - Exército Brasileiro \\ Recife - PE
}

\section{Introdução}

Desde as primeiras aulas de ciências no Ensino Fundamental, aprendemos que as plantas precisam de água, luz e sais minerais para viverem. Mas aí vem a pergunta: Será que qualquer cor de luz é vantajosa para a planta? A cor da luz influencia na fotossíntese?

A fotossíntese é um processo que consiste na conversão de gás carbônico e água em carboidratos, como a sacarose ou o amido. A presença da clorofila nas folhas é fundamental para que o processo ocorra. Segundo o que se sabe atualmente, as clorofilas dão a cor verde das plantas devido à baixa absorção desse comprimento de onda. Nas plantas verdes, como o feijoeiro, existem apenas as clorofilas tipos $\boldsymbol{a}$ e $\boldsymbol{b}$, (MARTINEZ, 2010) cujas moléculas diferenciam-se pelo radical. Ambas as clorofilas apresentam dois picos de absorção de luz: no vermelho (em torno de $665 \mathrm{~nm}$ ) e no azul (em torno de $465 \mathrm{~nm}$ ) (CHEN, 2011). Segundo Teixeira et al. (2004), a análise da clorofila auxilia no diagnóstico nutricional da planta.

Dessa forma, é possível realizar um experimento simples para observar o crescimento da planta, relacionando-o a uma eficiência do processo fotossintético e ao comprimento de onda da luz incidente. Caso a planta estivesse em condições luminosas adequadas, o processo fotossintético produziria "alimentos" para a planta, o que seria evidenciado pelo seu maior crescimento relativo. Por outro lado, em condições luminosas inadequadas, seriam produzidos menos "alimentos", e a planta cresceria relativamente menos. Esse experimento possui cunho científico claro, já que os alunos-executantes precisam realizar um experimento controlado por vários dias, além de necessitarem estudar conceitos de física, como espectro eletromagnético e cores dos objetos, e de biologia, como clorofila e fotossíntese. Para os professores, pode ser uma boa proposta para trabalhar a interdisciplinaridade entre física e biologia.

Para o experimento, utilizam-se mudas de feijão comum (Phaseolus vulgaris L.), por serem plantas resistentes, fáceis de plantar e de cuidar. Além disso, há, para os alunos, o resgate das experiências de plantar feijão em algodão, normalmente realizadas quando os alunos

\footnotetext{
${ }^{+}$What is the effect of color of light on photosynthesis?

* Recebido: agosto de2014. Aceito: dezembro de 2014.

${ }^{1}$ E-mail: ronaldo.melo@pq.cnpq.br
} 
iniciam seus estudos em ciências, no Ensino Fundamental. Alguns grãos de feijão são plantados em copos de plástico contendo algodão hidrófilo umedecido. Após, aproximadamente, duas semanas, quando as mudas estão crescidas e possuindo folhas e raízes, selecionam-se algumas de mesmo tamanho. Essas foram transferidas para um recipiente contendo terra e cobertas por papel celofane colorido (azul, verde, laranja, amarelo e vermelho), deixando, pelo menos, uma descoberta (Fig. 1). Então, são colocadas em um local iluminado, porém sem exposição direta ao sol ${ }^{2}$. Com isso, é possível observar quais comprimentos de onda de luz são mais eficientes para a fotossíntese, visualizando diretamente o desenvolvimento das plantas, comparativamente entre si e com a de referência (não recoberta com o celofane). Espera-se que os processos fotossintéticos das plantas recobertas pelos celofanes azuis e vermelhos sejam mais eficientes, ou seja, que essas plantas cresçam mais que as outras, recobertas pelos celofanes das outras cores. Uma observação importante consiste no fato de que é preciso colocar água para cada planta nas mesmas quantidades e no mesmo horário.

Podem-se utilizar os dados da Fig. 2 como espectros de transmissão ${ }^{3}$ luminosa dos filmes celofane comuns, encontrados nas papelarias. Com isso, é possível observar que as cores dos celofanes correspondem bem à faixa de comprimento de onda relativa a cada cor.

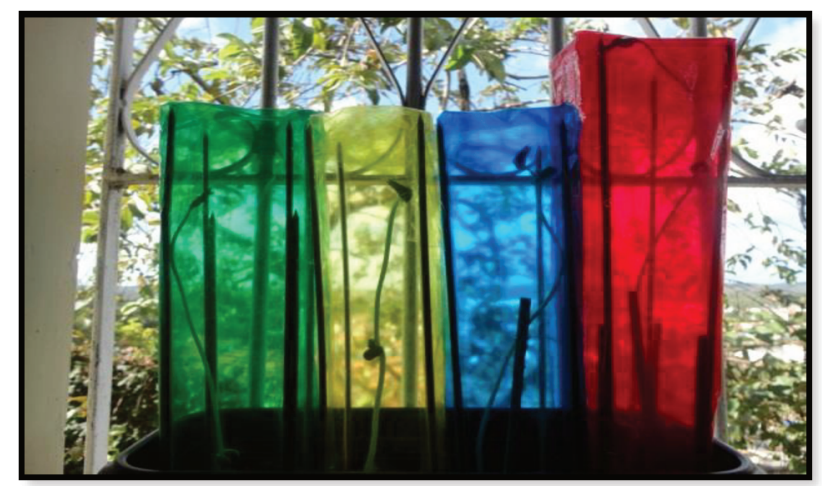

Fig. 1 - Mudas de feijão recobertas com filme celofane coloridos.

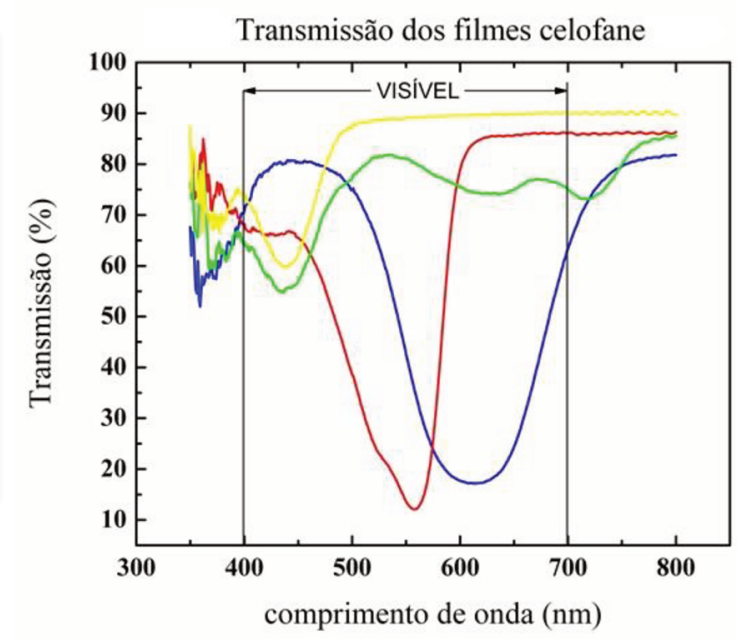

Fig. 2 - Espectro de transmissão de filmes de celofane utilizados nos experimentos.

Este experimento foi realizado em nosso Colégio e, conforme esperado, todos os alunos participantes obtiveram o mesmo resultado: todas as mudas recobertas com filtros azuis e vermelhos cresceram mais que as com filtros das outras cores. Isso ratifica a informação de que o crescimento da planta é dependente da eficiência do processo fotossintético, devido à presença das clorofilas tipos $\boldsymbol{a}$ e $\boldsymbol{b}$.

\footnotetext{
${ }^{2}$ Para evitar o clareamento do papel celofane.

${ }^{3}$ Medidas realizadas no Laboratório de Óptica Não-Linear de Optoeletrônica do Departamento de Física da UFPE, com autorização do professor Cid Bartolomeu de Araújo.
} 
As conclusões comuns destacadas pelos alunos que realizaram os experimentos podem ser resumidas da seguinte maneira:

- Observou-se a interdependência da presença de clorofila com o desenvolvimento da planta e a cor da luz incidente, corroborando o previsto por outros autores [Teixeira et al. (2004)].

- Em todos os experimentos, observou-se que as plantas submetidas à iluminação azul ou vermelha se desenvolveram mais rapidamente e atingiram maiores comprimentos que as outras iluminadas pelas outras cores.

- Destacou-se o pouco desenvolvimento relativo das plantas iluminadas pela cor verde, o que evidencia a baixa absorção dos comprimentos de onda desta região do espectro eletromagnético. Concordando com o conceito físico de cor do objeto, utilizado atualmente para associar a cor verde às plantas: já que se o comprimento de onda verde não é absorvido, é refletido.

Quanto às abordagens interdisciplinares, podem-se retirar as seguintes conclusões:

- Do ponto de vista da disciplina de Física, a atividade demonstra ser bastante vantajosa ao discutir o conceito de espectro eletromagnético. A prática permite que os alunos entendam que a luz do Sol pode ser decomposta em todas as cores do espectro de luz visível.

- Do ponto de vista da disciplina de Biologia, demonstra-se que a fotossíntese é um processo fundamental para o crescimento das plantas. Além disso, há uma dependência importante na cor da luz que ilumina a planta.

- O trabalho demonstra que a interdisciplinaridade é viável, motivadora e desafiadora. Há a necessidade de que todos os envolvidos procurem entender o projeto de forma holística. Também há um aprofundamento em discussões afetas às disciplinas envolvidas e permitindose atuar no processo ensino-aprendizagem de forma mais completa, ora como professor, ora como aluno.

\section{Agradecimentos}

Os autores agradecem a Luiz Rodrigues e Renan Freitas, respectivamente professores de Biologia e Língua Portuguesa do Colégio Militar do Recife, pelas contribuições e observações. Também agradecem ao professor Cid Bartolomeu de Araújo, do Departamento de Física da UFPE, pelo apoio na utilização do espectrômetro de transmissão.

\section{Referências}

CHEN, M.; BLANKENSHIP, R. E. Expanding the solar spectrum used by Photosynthesis. Trends in Plant Science, v. 16, n. 8, p. 427-431, 2011.

MARTINEZ, M. Clorofila. Infoescola, 2010. Disponível em:

<http://www.infoescola.com/plantas/clorofila/>. Acesso em: 2 set. 2012. 
TEIXEIRA, I. R.; BORÉM, A.; ANDRADE, M. J. B.; GIÚDICE, M. P.; CECON, P. R. Teores de clorofila em plantas de feijoeiros influenciadas pela adubação com manganês e zinco. Acta Scientiarum, Agronomy, v. 26, n. 2, p. 147-152, 2004. 